Article

\title{
Resistance Change Mechanism of Electronic Component Mounting through Contact Pressure Using Elastic Adhesive
}

\author{
Takashi Sato ${ }^{1}$, Tomoya Koshi ${ }^{2}$ and Eiji Iwase ${ }^{1, *(1)}$ \\ 1 Department of Applied Mechanics, Waseda University, 3-4-1 Okubo, Shinjuku-ku, Tokyo 169-8555, Japan; \\ sato@iwaselab.amech.waseda.ac.jp \\ 2 Sensing System Research Center, National Institute of Advanced Industrial Science and Technology (AIST), \\ 1-1-1 Higashi, Tsukuba 305-8565, Japan; t.koshi@aist.go.jp \\ * Correspondence: iwase@waseda.jp; Tel.: +81-03-5286-2741
}

Received: 19 May 2019; Accepted: 10 June 2019; Published: 14 June 2019

\begin{abstract}
For mounting electronic components through contact pressure using elastic adhesives, a high contact resistance is an inevitable issue in achieving solderless wiring in a low-temperature and low-cost process. To decrease the contact resistance, we investigated the resistance change mechanism by measuring the contact resistance with various contact pressures and copper layer thicknesses. The contact resistivity decreased to $4.2 \times 10^{-8} \Omega \cdot \mathrm{m}^{2}$ as the contact pressure increased to $800 \mathrm{kPa}$ and the copper layer thickness decreased to $5 \mu \mathrm{m}$. In addition, we measured the change in the total resistance with various copper layer thicknesses, including the contact and wiring resistance, and obtained the minimum combined resistance of $123 \mathrm{~m} \Omega$ with a copper-layer thickness of $30 \mu \mathrm{m}$ using our mounting method. In this measurement, a low contact resistance was obtained with a 5- $\mu \mathrm{m}$-thick copper layer and a contact pressure of $200 \mathrm{kPa}$ or more; however, there is a trade-off with respect to the copper layer thickness in obtaining the minimum combined resistance because of the increasing wiring resistance. Subsequently, based on these measurements, we developed a sandwich structure to decrease the contact resistance, and a contact resistivity of $8.0 \times 10^{-8} \Omega \cdot \mathrm{m}^{2}$ was obtained with the proposed structure.
\end{abstract}

Keywords: surface mounting; flexible electronic device; contact resistance; contact pressure

\section{Introduction}

Recently, flexible electronic devices, such as flexible displays [1-5], batteries [6-10], and sensor arrays [11-15], have been developed by many research groups [16-22]. In particular, healthcare monitoring systems using flexible electronic devices, which can adhere to human skin, have attracted considerable interest. In previous studies, to mount electronic components on a flexible circuit, solders $[23,24]$ or conductive adhesives $[25,26]$ were used, and the contact resistivity is on the order of $10^{-11} \Omega \cdot \mathrm{m}^{2}$ in solders and $10^{-9} \Omega \cdot \mathrm{m}^{2}$ in conductive adhesives. The conductivity is the contact resistance per unit contact area. Although a simple fabrication process is required for high-mix, low-volume manufacturing to achieve individual optimization of healthcare monitoring systems, these fabrication processes are quite complicated owing to both the dispensing and patterning processes. Moreover, polyurethane and rubbers are mainly used for substrates of stretchable circuits, but their low heat resistance causes problems in soldering and misalignment of electronic components owing to thermal expansion. To solve these issues, solderless mounting methods via contact pressure using an elastic adhesive $[27,28]$ were proposed as a new simple manufacturing processes. These methods do not require complex mounting processes and heating. Their applicability is, however, hindered by their 
high contact resistance because the electrical connections are based on physical contact. The mechanism for controlling resistance change to achieve low contact resistance is still not clear.

Therefore, in this study, we first considered the mechanism of contact resistance change to clarify the causes of this change. Then, the change in the contact resistance was experimentally measured to investigate the relationship between the expected causes and the contact resistance. Second, we developed a new mounting structure to obtain a high compression force to decrease the contact resistance and evaluated the contact resistance.

\section{Materials and Methods}

First, the basic mechanism of contact resistance was considered. Contact resistance is the sum of the constriction resistance and film resistance. The constriction resistance is influenced by the concentration of current that flows into the real contact area between the conductor surfaces. The film resistance is influenced by chemical films, such as oxide films, oil, and dirt films, on the conductor surface. In this research, we focused on constriction resistance because the constriction resistance must be dominant in this solderless mounting of electronic components; constriction resistance would decrease as the real contact area increased. Figure 1a shows the schematic image of the contact resistance change in the solderless mounting method. The electrical connection is formed via contact of surface-mounted electronic components with contact pads of the metal layer, where the elastic adhesives provide restoring forces to press them. For example, a surface-mounted electronic component is held by elastic adhesives sandwiching from above and below in the sandwich structure proposed in this research, shown in Figure 1c. The important feature here is the surface shape of the electrode of the electronic components, as shown in Figure 1b. Most of the electrodes in surface-mounted electronic components are generally not perfectly flat but slightly curved and rough, and so are the chip resistors. These electrodes are gradual convex shapes $400-\mu \mathrm{m}$ wide and $20-\mu \mathrm{m}$ high, and the surface roughness of the electrodes is less than a few micrometers. Figure 1 shows the decrease in the contact resistance caused by the change in the contact area when an electronic component is pressed against the contact pads. On applying the contact pressure, the contact pad deforms and the contact area with the electrodes of the component is enlarged. Hence, Figure 1c suggests that the thinner metal electrodes exhibit large deformation, and thus they make contact with the electrodes to lower the contact resistance. Nevertheless, the thinner metal layers show larger resistance and are susceptible to damage owing to excessive deformation. Therefore, it is important to investigate contact pressures to obtain a sufficiently small contact resistance with different metal layer thicknesses and determine the thickness when the sum of the contact resistance and wiring resistance is the lowest.

To evaluate the effect of the contact pressure and thickness of the metal layer on the contact resistance, we experimentally measured the change in the contact resistance considering the contact pressure and thickness of the metal layer. Figure 2a shows schematic images with the dimensions of the experimental sample. The acrylic foam double sided adhesive sheet (Y-4905J, 3M, Maplewood, MN, USA) with a thickness of $0.5 \mathrm{~mm}$ was cut to a length of approximately $30 \mathrm{~mm}$ and width of $20 \mathrm{~mm}$ and affixed to a glass plate. A metal layer was patterned by laser cutting to a length of $10 \mathrm{~mm}$ and width of $5 \mathrm{~mm}$ using rolled copper films (Nilaco Co., Tokyo, Japan) with thicknesses of 5, 10, 30, and $50 \mu \mathrm{m}$. The metal layers were transferred onto the elastic adhesive with a gap of $1 \mathrm{~mm}$, and a surface-mounted chip resistor (MCR10EZPJ000, ROHM Co., Kyoto, Japan) was placed on it. Figure 2b shows optical images of a sample used in the experiment. Figure 3a,b shows optical images of the apparatus used to measure the change in the contact resistance. The sample was fixed onto a movable stage with polyimide tape to be pushed by a compression testing machine (ZTS-20N, IMADA Co., Aichi, Japan); this machine has a pole with a small and flat end to press the chip resistor. The movable stage went up to apply pressure on the chip resistor, and the value of the pressure was monitored by the compression testing machine. The contact resistance was measured using a source meter (2614B, Keithley Instruments, Cleveland, $\mathrm{OH}, \mathrm{USA}$ ) with four-terminal sensing. The applied voltage was $10 \mathrm{mV}$, and the current compliance was $100 \mathrm{~mA}$. Figure 3c shows the backside images of the experimental sample without and 
with pushing by a compression testing machine. With pressing pressure, the chip resistor sunk into the contact pad regions of the metal layer, and the contact pads largely deformed along the surface of the chip resistor. To measure and compare the total resistance, contact resistance $\left(R_{\text {contact }}\right)$, and wiring resistance of the metal layer $\left(R_{\text {wiring }}\right)$, we fabricated a sample device composed of a surface-mounted electronic component with a metal layer of contact pads and wave-shaped wirings and an elastic adhesive (Figure 4). We employed a chip resistor (MCR10EZPJ000, ROHM Co., Kyoto, Japan) with an internal resistance $\left(R_{\text {internal }}\right)$ of $11 \mathrm{~m} \Omega$, a $0.5-\mathrm{mm}$-thick acrylic foam adhesive sheet, and a metal layer of rolled copper films with thicknesses of $5,10,30$, and $50 \mu \mathrm{m}$ for the device fabrication. The copper films were patterned to form contact pads and wave-shaped wirings with a width of $1.0 \mathrm{~mm}$ and radius of $0.9 \mathrm{~mm}$. The contact pads were fabricated with a length of $2.8 \mathrm{~mm}$ and width of $2.8 \mathrm{~mm}$ at both ends of the wiring. The patterned copper film was placed on the adhesive sheet with a gap of $1 \mathrm{~mm}$. $R_{\text {wiring }}$ of the wave-shaped electrodes was measured by the source meter with four-terminal sensing. Total resistance $\left(R_{\text {total }}\right)$ is the sum of $R_{\text {contact }}, R_{\text {wiring, }}$ and $R_{\text {internal }}$.
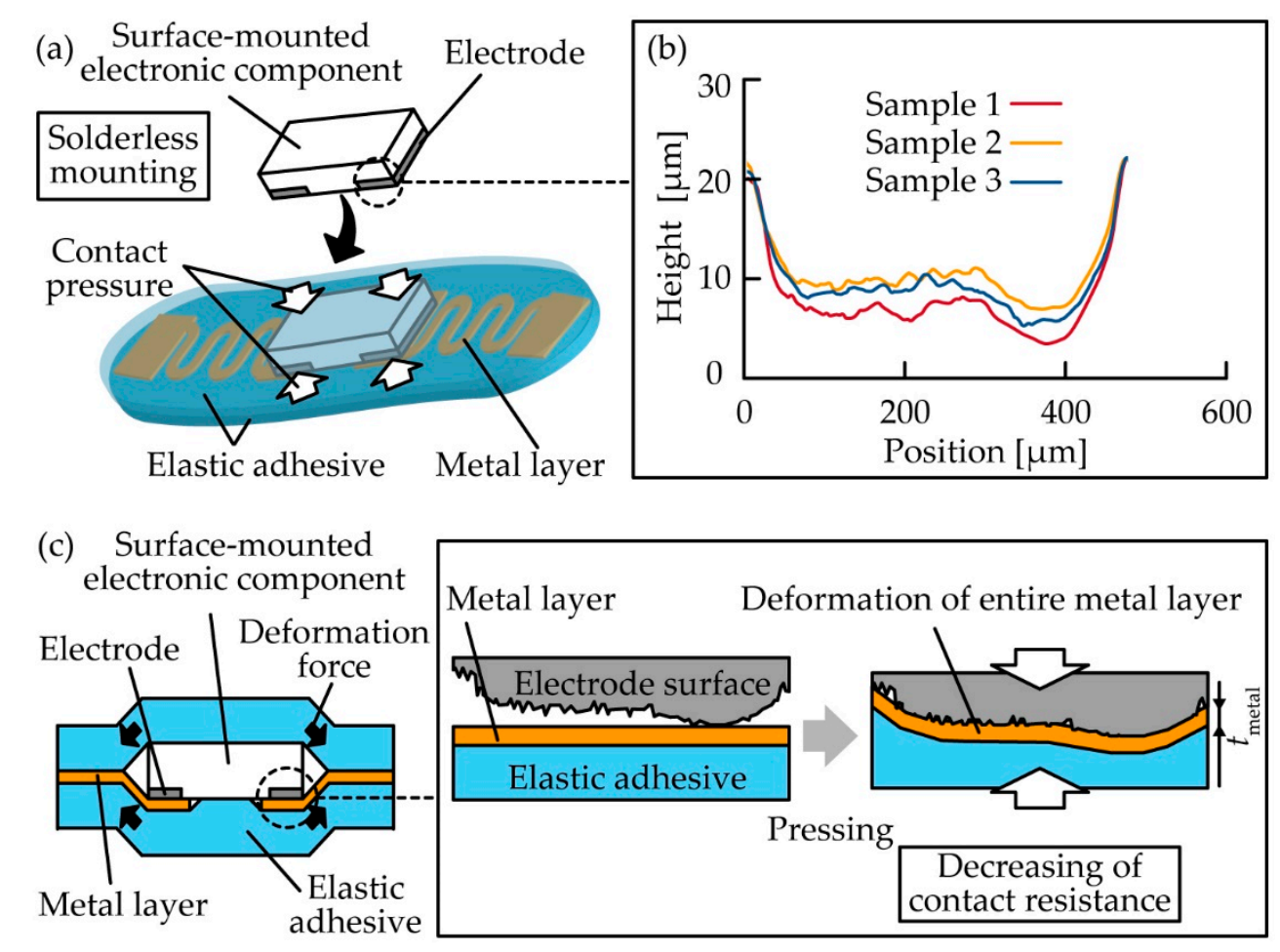

Figure 1. (a) Schematic image of electronic component mounting through contact pressure using an elastic adhesive; (b) electrode surface profiles of surface-mounted electronic component; (c) deformation of contact pad of metal layer of elastic adhesive sheet by gradually increasing contact pressure. 
(a)

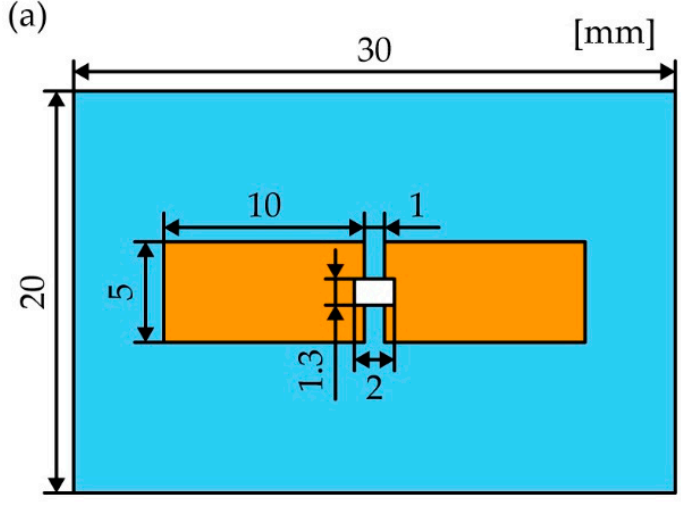

Surface mounted electronic component

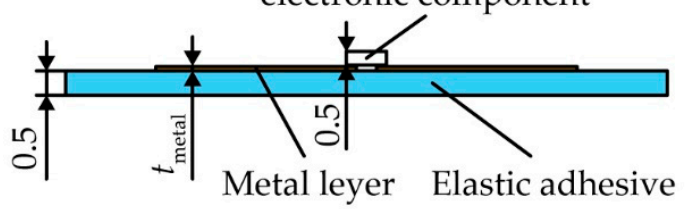

(b)

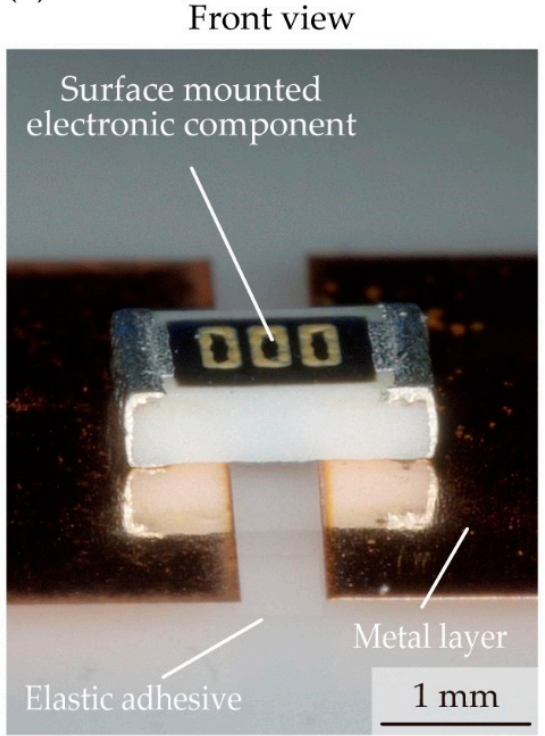

Figure 2. (a) Schematic images of experimental sample; (b) optical image of sample.

(a)

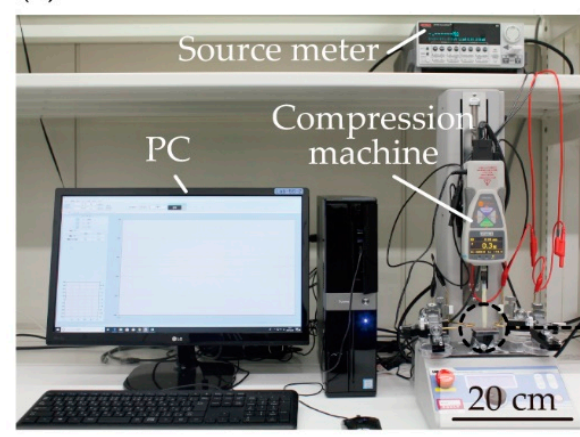

(c) (b)

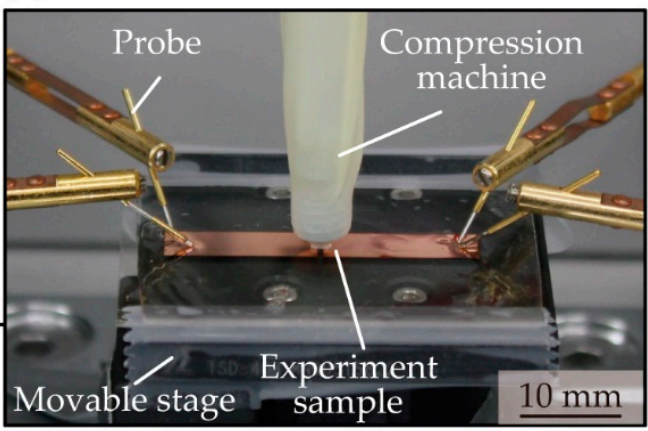

Back view

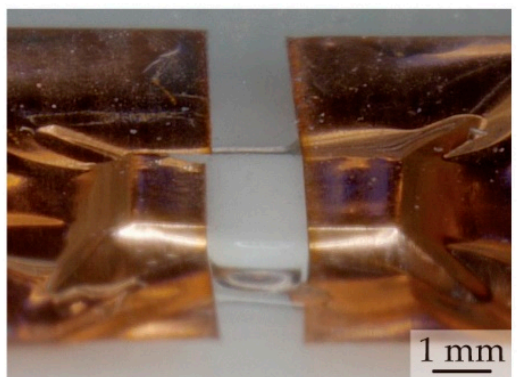

Figure 3. Optical images of experimental apparatus used to measure the change in contact resistance. (a) Optical image of apparatus; (b) optical image of enlarged view of experimental sample pressed by compression testing machine; (c) optical images of experimental sample with and without pushing. 


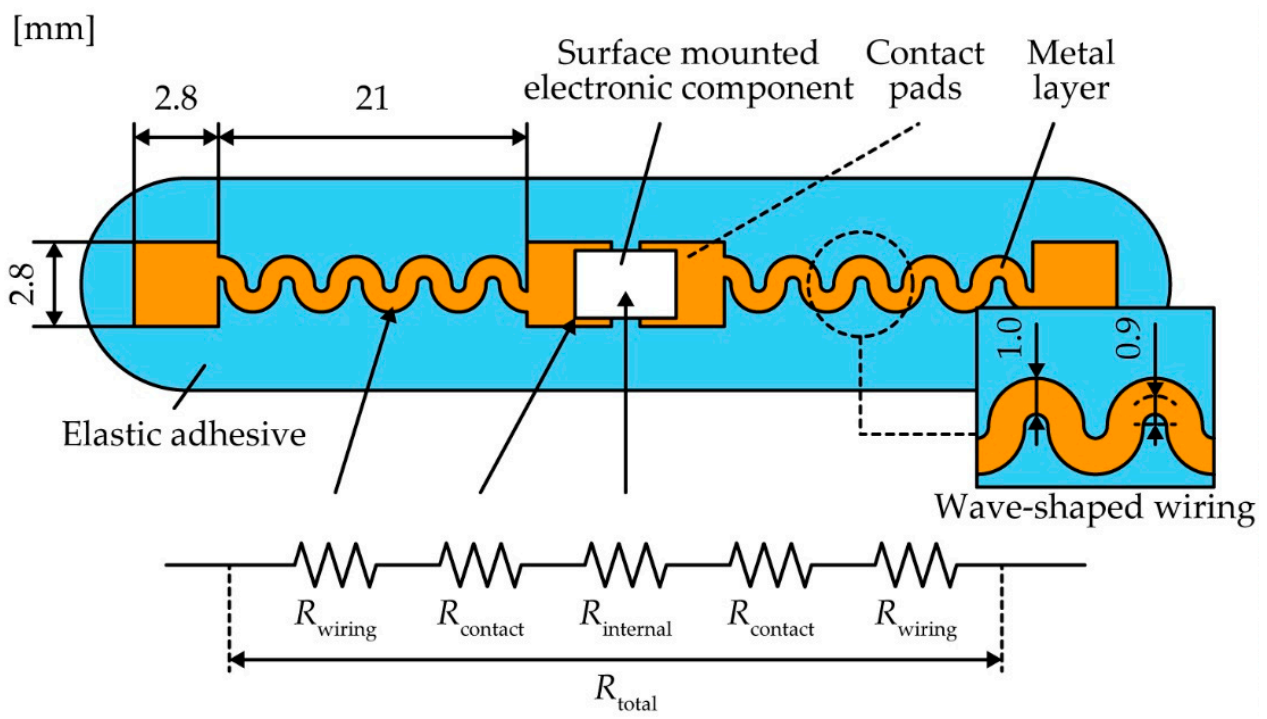

Figure 4. Schematic image of sample device.

Based on the results obtained by measuring the above parameters, we fabricated several types of electrode structures to obtain lower resistance using higher pressure and investigated the relationship between the structures and compression force. We fabricated several samples of the simple adhesive, concave, and sandwich structures and compared the contact resistivity of each structure. In this measurement, we used an elastic adhesive with a thickness of $0.5 \mathrm{~mm}$ and a metal layer of rolled copper films with a thickness of $5 \mu \mathrm{m}$ for device fabrication. The depth of the concave region was $0.5 \mathrm{~mm}$ because we used two elastic adhesive sheets to make the concave structure. The metal layers were patterned to the contact pad with a length of $10 \mathrm{~mm}$ and width of $5 \mathrm{~mm}$ formed via laser cutting. Then, the electrodes were transferred onto the elastic adhesive with a gap of $1 \mathrm{~mm}$, and a 0.5 -mm-thick chip resistor (MCR10EZPJ000, ROHM Co., Kyoto, Japan) as an electrical component was placed on it. The contact resistivity $\left(r_{\text {contact }}\right)$ was measured using the source meter $10 \mathrm{~min}$ after connecting. In addition, we measured the contact resistivity in the sandwich structure with other surface-mounted electronic components to investigate the encapsulation of the sandwich structure. A 0.6-mm-thick chip resistor (RK73ZW2HTTE, KOA CORPORATION, Tokyo, Japan), a 0.64-mm-thick chip resistor (3522ZR, TE Connectivity Ltd., Kanagawa, Japan), and a 1.1-mm-thick chip resistor (WSL251200000ZEA9, Vishay Intertechnology, Inc., Pennsylvania, USA) were mounted in a sandwich structure in the same manner as the chip resistor (MCR10EZPJ000, ROHM Co., Kyoto, Japan). Finally, to demonstrate the application of the sandwich structure for flexible electrical circuits, we fabricated an electronic device. A surface-mounted light emitting diode (LED) chip (OSR50805C1C, OptoSupply, N.T., Hong Kong, China) was embedded in the sandwich structure using a 5 - $\mu \mathrm{m}$-thick copper film and 0.5 -mm-thick acrylic foam adhesive sheets to form an electrical contact.

\section{Results and Discussion}

Figure 5 shows the change in the contact resistivity $\left(r_{\text {contact }}\right)$ against various contact pressures $\left(P_{\text {contact }}\right)$ with various thicknesses of the copper contact pads $\left(t_{\text {metal }}\right) . r_{\text {contact }}$ is the contact resistance per unit contact area. $r_{\text {contact }}$ was much higher than $10^{-2} \Omega \cdot \mathrm{m}^{2}$ at $0 \mathrm{kPa}$; it then dramatically decreased to $10^{-7} \Omega \cdot \mathrm{m}^{2}$ as $P_{\text {contact }}$ increased for each $t_{\text {metal }}$. Then, $r_{\text {contact }}$ gradually decreased to as low as approximately $10^{-8} \Omega \cdot \mathrm{m}^{2}$ after $P_{\text {contact }}$ increased. Moreover, the contact pressure values with an $r_{\text {contact }}$ of $1.0 \times 10^{-7} \Omega \cdot \mathrm{m}^{2}$ for each $t_{\text {metal }}$ are shown in Figure 5 . The pressure value for an $r_{\text {contact }}$ of $1.0 \times 10^{-7} \Omega \cdot \mathrm{m}^{2}$ decreased as $t_{\text {metal }}$ decreased; these results indicate that the thin electrode decreases the pressure value at an $r_{\text {contact }}$ of $1.0 \times 10^{-7} \Omega \cdot \mathrm{m}^{2}$. The sample device fabricated to measure and compare the total resistance, contact resistance $\left(R_{\text {contact }}\right)$, and wiring resistance of metal layer $\left(R_{\text {wiring }}\right)$ is shown in Figure 6. The copper films patterned to form contact pads and wave-shaped wirings are 
shown in Figure 4. $R_{\text {contact }}$ at a pressure of $800 \mathrm{kPa}$ was measured as shown in Figure 3 . Figure 6 shows $R_{\text {contact }}, R_{\text {wiring }}, R_{\text {internal }}$, and $R_{\text {total }}$ for various values of $t_{\text {metal }}$. $R_{\text {contact }}$ decreased from 131.5 to $49.6 \mathrm{~m} \Omega$ as $t_{\text {metal }}$ decreased from 50 to $5 \mu \mathrm{m}$. $R_{\text {wiring }}$ increased from 23.5 to $215 \mathrm{~m} \Omega$ as $t_{\text {metal }}$ decreased. $R_{\text {total }}$ decreased as $t_{\text {metal }}$ decreased from 50 to $30 \mu \mathrm{m}$, and the resistance reached a minimum value of $123 \mathrm{~m} \Omega$ at a $t_{\text {metal }}$ value of $30 \mu \mathrm{m}$. $R_{\text {total }}$ remained the same as $t_{\text {metal }}$ decreased from 30 to $10 \mu \mathrm{m}$, and then increased to $275 \mathrm{~m} \Omega$ as $t_{\text {metal }}$ decreased from 10 to $5 \mu \mathrm{m}$. Therefore, with these dimensions of the device, $R_{\text {total }}$ reached a minimum value in the $t_{\text {metal }}$ range $30-10 \mu \mathrm{m}$. This result indicates a trade-off point with respect to $t_{\text {metal }}$ for minimizing $R_{\text {total }}$.

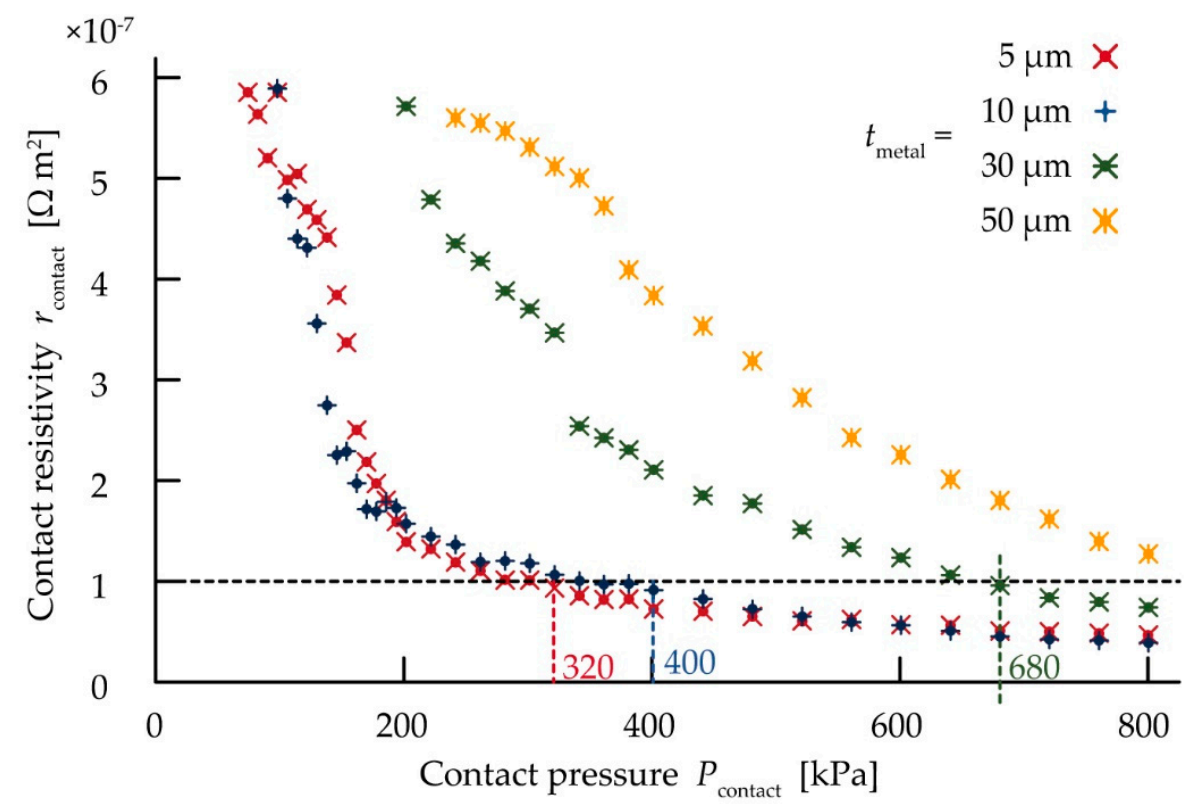

Figure 5. Relationship between contact pressure and contact resistivity with various copper layer thicknesses. The number of trials in each thickness was five.

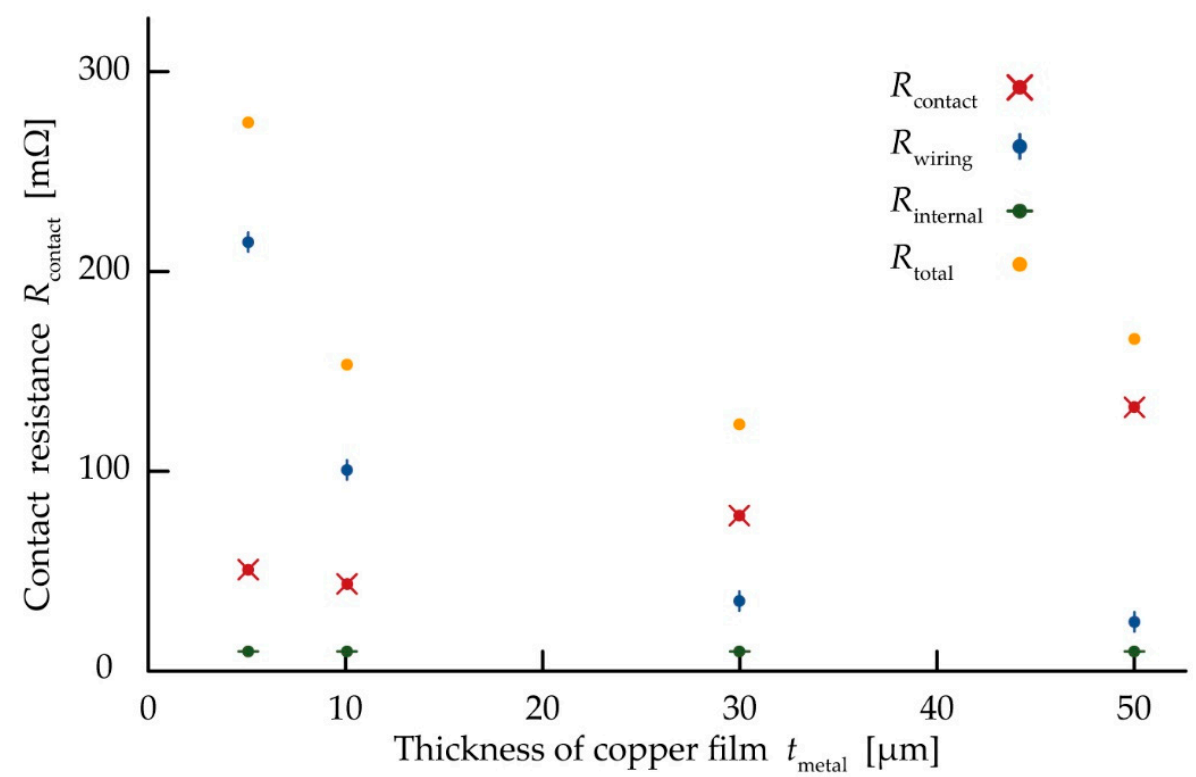

Figure 6. Relationship between thicknesses of copper layer $t_{\text {metal }}$, contact resistance $R_{\text {contact, wiring }}$ resistance $R_{\text {wiring }}$, internal resistance $R_{\text {internal }}$, and total resistance $R_{\text {total }}$. Five trials were carried out to measure $R_{\text {contact }}$ for each thickness. Two trials were carried out to measure $R_{\text {wiring }}$ and $R_{\text {internal }}$ for each thickness. 
Figure 7 shows schematics and optical images of the structures based on three different designs with the considered contact pressure and metal layer thickness for electrical connection from the above measurement results. In this measurement, we used an elastic adhesive with a thickness of $0.5 \mathrm{~mm}$, a metal layer of rolled copper films with a thickness of $5 \mu \mathrm{m}$, and a surface-mounted electronic component with a height of $0.5 \mathrm{~mm}$ for device fabrication. Figure $7 \mathrm{a}$ is a simple adhesive structure, in which a surface-mounted electronic component is simply placed on the contact pads of the metal layer on the elastic adhesive. In this design, first, the electronic component is pressed against the contact pads through an external force, and the electronic component contacts the elastic adhesive. Then, after removing the external force, the elastic adhesive under the electronic component is deformed, and the restoring force of the deformed elastic adhesive presses the electronic component against the contact pads. As a result, an electrical connection is caused because of the restoring force. The restoring force based on the deformation of the elastic adhesive is weak, however, and the contact resistance is expected to be high. Therefore, we proposed a concave structure and a sandwich structure to increase the restoring force and obtain lower contact resistance in different ways. Figure $7 \mathrm{~b}$ shows schematic images and an optical image of a concave structure, which is used with the non-uniform thickness substrate of the elastic adhesive. Owing to the concave shape of the elastic adhesive under the surface-mounted electronic component, the bottom of the concave shape of the elastic adhesive is stretched more, and the electronic component is pulled down stronger than in the simple structure. Figure 7c shows schematic images and an optical image of a sandwich structure. A surface-mounted electronic component is placed on the contact pads on a base layer of the elastic adhesive; then, an upper layer containing the elastic adhesive is placed on the electronic component and pressed via an external force to contact the base layer strongly. After removing the external force, the elastic adhesives are stretched to press the electronic component against the contact pads by providing a restoring force.

Further, we fabricated testing structures and obtained contact resistivity $\left(r_{\text {contact }}\right)$ values of $2.5 \times 10^{-2}, 1.9 \times 10^{-2}$, and $8.0 \times 10^{-8} \Omega \cdot \mathrm{m}^{2}$ for the simple adhesive, concave, and sandwich structures, respectively, as shown in Figure $8 \mathrm{a}$. Though the contact pressure value in these structures cannot be directly measured because the contact pressure is an internal pressure, we can estimate the contact pressure value from the contact resistance value based on the relationship between the contact pressure and the contact resistance explained in Figure 5. According to the values of the contact resistance in Figure $8 \mathrm{a}$, the values of the contact pressure were estimated at less than approximately $60 \mathrm{kPa}$ for the simple adhesive and concave structures, and more than approximately $320 \mathrm{kPa}$ for the sandwich structure. The contact resistivity in the sandwich structure was on the order of $10^{6} \Omega \cdot \mathrm{m}^{2} \mathrm{lower}$ than that in the simple adhesive structure. This result indicates that the contact pressure was not sufficient to obtain low contact resistivity with the simple adhesive structures or concave structure. In the case of the concave structure, though high contact pressure was expected, it was considered that the elastic adhesive under the metal layer was deformed via tilting, and the contact pressure was decreased. The high contact pressure is also considered to be able to prevent the electrical component from slipping off the contact pads of the metal layer when a flexible electronic device using contact pressure is stretched or bent. Therefore, we are considering that the contact pressure is important for not only the contact resistance but also the mechanical stability. In addition, we confirmed that the contact resistivity in electronic components with different heights between 0.5 and $1.1 \mathrm{~mm}$ mounted by the sandwich structure was less than $5 \times 10^{-7} \Omega \cdot \mathrm{m}^{2}$. Therefore, our method can use electronic components with different heights. Figure $8 \mathrm{~b}$ shows that an LED device fabricated using a sandwich structure can function as an electronic device. In this experiment, the light intensity of the LED device was not affected by the acrylic foam adhesive sheet because of the high transparency. We confirmed that the chip LED continued emitting light for ten hours. Because the chip LED seemed to keep almost same brightness ten hours later, we could consider that the contact resistivity of the chip LED was kept on the order of $10^{-8} \Omega \cdot \mathrm{m}^{2}$ for more than ten hours. These results indicate that a low contact resistance can be obtained using the proposed sandwich structure, which facilitates the development of flexible electrical circuits through a simple and low-cost process. 
(a)
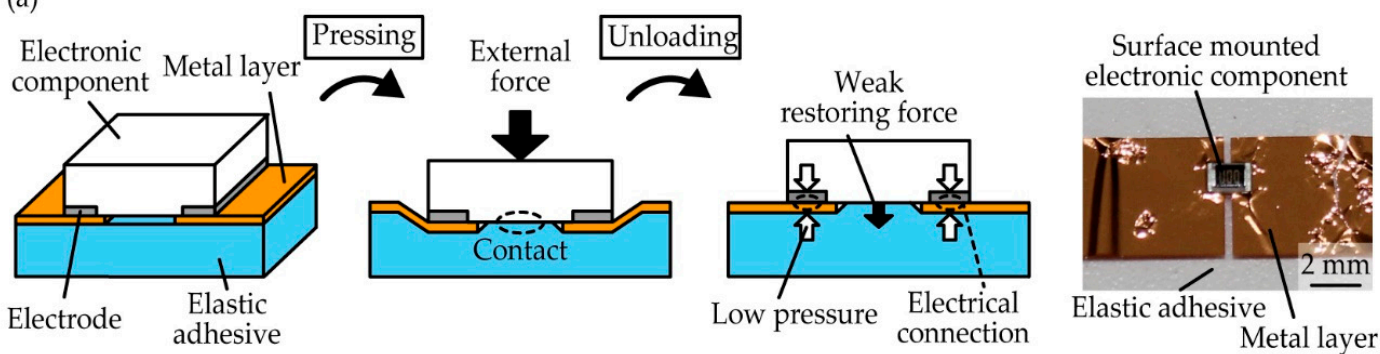

(b)
Electronic
component
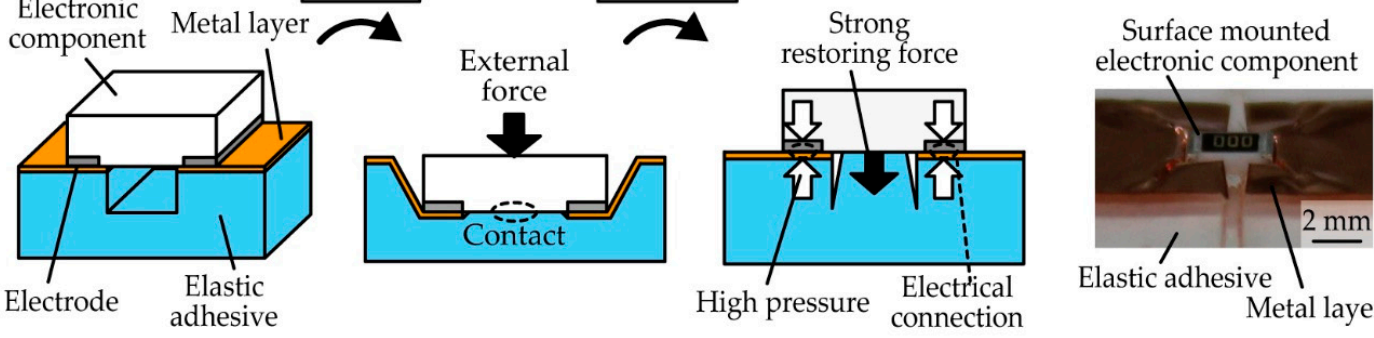

(c)
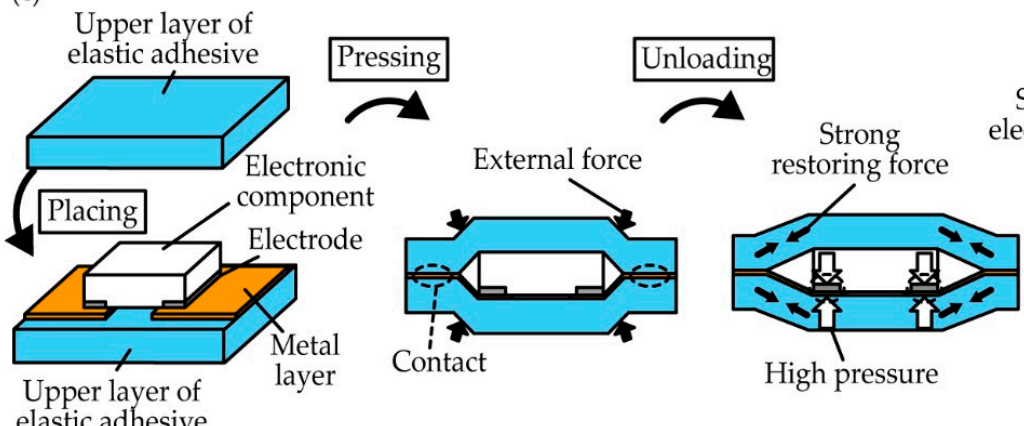

High pressure

Surface mounted electronic component Metal layer

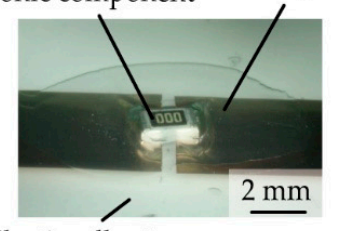

elastic adhesive

Figure 7. Schematic images and optical images of the (a) simple adhesive structure, (b) concave structure, and (c) sandwich structure.

(a)

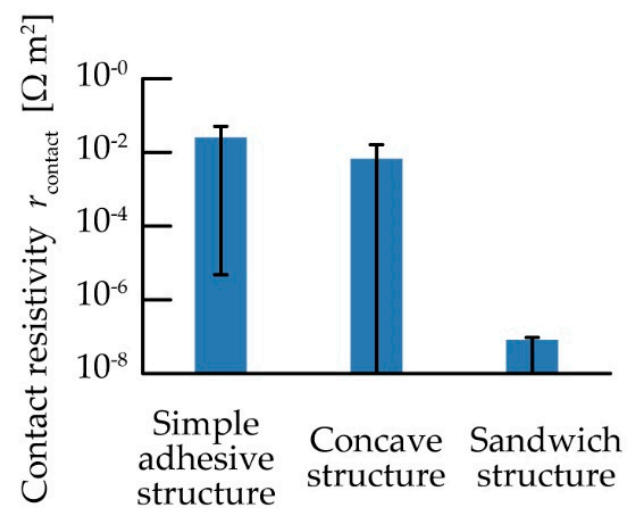

(b)

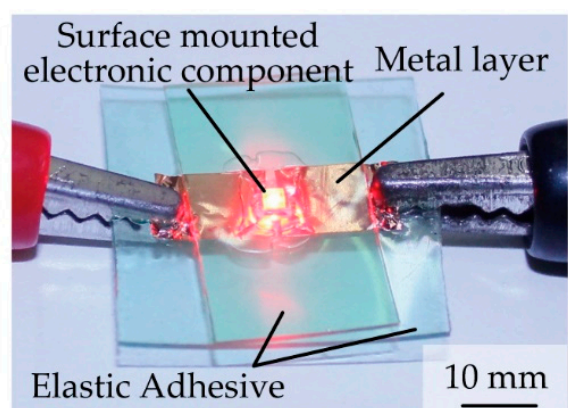

Figure 8. (a) Comparison of contact resistivity values in simple adhesive, concave, and sandwich structures; (b) flexible electronic device with light emitting diode (LED) chip mounted on a sandwich structure.

\section{Conclusions}

We achieved a sufficiently small contact resistivity of $8.0 \times 10^{-8} \Omega \cdot \mathrm{m}^{2}$ between a surface-mounted electronic component and a flexible circuit substrate through pressure using an elastic adhesive. 
First, we investigated the mechanism of contact resistance change to obtain a low contact resistance. The change in contact resistance was measured at various pressures and using copper films having thicknesses of $5,10,30$, and $50 \mu \mathrm{m}$. As a result, the contact resistivity decreased to below $10^{-2} \Omega \cdot \mathrm{m}^{2}$ when the pressure increased to approximately $200 \mathrm{kPa}$. Above $200 \mathrm{kPa}$, the contact resistivity gradually decreased to $10^{-8} \Omega \cdot \mathrm{m}^{2}$ as the contact pressure increased. Based on these measurement results, we designed a sandwich structure to obtain a resistivity of $8.0 \times 10^{-8} \Omega \cdot \mathrm{m}^{2}$. Moreover, we fabricated a simple flexible electronic device with an chip LED using the sandwich structure, and the chip LED continued emitting light for ten hours after mounting.

Author Contributions: T.S., T.K., and E.I. conceived and designed the experiments; T.S. performed the experiments; T.S. and T.K. analyzed the data; T.S. wrote the paper; T.K. and E.I. reviewed and edited the paper; E.I. supervised the research.

Funding: This research was partially supported by JST CREST Grant Number JPMJCR16Q5, Japan.

Acknowledgments: The author would like to acknowledge Shunsuke Yamada at Waseda University for his support.

Conflicts of Interest: The authors declare no conflict of interest.

\section{References}

1. Abu-Khalaf, J.; Saraireh, R.; Eisa, S.; Al-Halhouli, A. Experimental characterization of inkjet-printed stretchable circuits for wearable sensor applications. Sensors 2018, 18, 3476. [CrossRef] [PubMed]

2. Choi, M.; Jang, B.; Lee, W.; Lee, S.; Kim, T.W.; Lee, H.J.; Kim, J.H.; Ahn, J.H. Stretchable Active matrix inorganic light-emitting diode display enabled by overlay-aligned roll-transfer printing. Adv. Funct. Mater. 2017, 27, 1606005. [CrossRef]

3. Yokota, T.; Zalar, P.; Kaltenbrunner, M.; Jinno, H.; Matsuhisa, N.; Kitanosako, H.; Tachibana, Y.; Yukita, W.; Koizumi, M.; Someya, T. Ultraflexible organic photonic skin. Sci. Adv. 2016, 2, e1501856. [CrossRef] [PubMed]

4. Sekitani, T.; Nakajima, H.; Maeda, H.; Fukushima, T.; Aida, T.; Hata, K.; Someya, T. Stretchable active-matrix organic light-emitting diode display using printable elastic conductors. Nat. Mater. 2009, 8, 494-499. [CrossRef] [PubMed]

5. Hu, X.; Krull, P.; De Graff, B.; Dowling, K.; Rogers, J.A.; Arora, W.J. Stretchable inorganic-semiconductor electronic systems. Adv. Mater. 2011, 23, 2933-2936. [CrossRef] [PubMed]

6. Liu, B.; Zhang, J.; Wang, X.; Chen, G.; Chen, D.; Zhou, C.; Shen, G. Hierarchical three-dimensional $\mathrm{ZnCo}_{2} \mathrm{O}_{4}$ nanowire arrays/carbon cloth anodes for a novel class of high-performance dlexible lithium-ion batteries. Nano Lett. 2012, 12, 3005-3011. [CrossRef]

7. Lee, J.W.; Xu, R.; Lee, S.; Jang, K.-I.; Yang, Y.; Banks, A.; Yu, K.J.; Kim, J.; Xu, S.; Ma, S.; et al. Soft, thin skin-mounted power management systems and their use in wireless thermography. Proc. Natl. Acad. Sci. USA 2016, 113, 6131-6136. [CrossRef]

8. El-Kady, M.F.; Kaner, R.B. Scalable fabrication of high-power graphene micro-supercapacitors for flexible and on-chip energy storage. Nat. Commun. 2013, 4, 1475. [CrossRef]

9. Xu, S.; Zhang, Y.; Cho, J.; Lee, J.; Huang, X.; Jia, L.; Fan, J.A.; Su, Y.; Su, J.; Zhang, H.; et al. Stretchable batteries with self-similar serpentine interconnects and integrated wireless recharging systems. Nat. Commun. 2013, 4, 1543. [CrossRef]

10. Pushparaj, V.L.; Shaijumon, M.M.; Kumar, A.; Murugesan, S.; Ci, L.; Vajtai, R.; Linhardt, R.J.; Nalamasu, O.; Ajayan, P.M. Flexible energy storage devices based on nanocomposite paper. Proc. Natl. Acad. Sci. USA 2007, 104, 13574-13577. [CrossRef]

11. Lipomi, D.J.; Vosgueritchian, M.; Tee, B.C.K.; Hellstrom, S.L.; Lee, J.A.; Fox, C.H.; Bao, Z. Skin-like pressure and strain sensors based on transparent elastic films of carbon nanotubes. Nat. Nanotechnol. 2011, 6, 788-792. [CrossRef] [PubMed]

12. Kim, J.; Lee, M.; Shim, H.J.; Ghaffari, R.; Cho, H.R.; Son, D.; Jung, Y.H.; Soh, M.; Choi, C.; Jung, S.; et al. Stretchable silicon nanoribbon electronics for skin prosthesis. Nat. Commun. 2014, 5, 1-11. [CrossRef] [PubMed] 
13. Someya, T.; Sekitani, T.; Iba, S.; Kato, Y.; Kawaguchi, H.; Sakurai, T. A large-area, flexible pressure sensor matrix with organic field-effect transistors for artificial skin applications. Proc. Natl. Acad. Sci. USA 2004, 101, 9966-9970. [CrossRef] [PubMed]

14. Yokota, T.; Inoue, Y.; Terakawa, Y.; Reeder, J.; Kaltenbrunner, M.; Ware, T.; Yang, K.; Mabuchi, K.; Murakawa, T.; Sekino, M.; et al. Ultraflexible, large-area, physiological temperature sensors for multipoint measurements. Proc. Natl. Acad. Sci. USA 2015, 112, 14533-14538. [CrossRef] [PubMed]

15. Shih, W.P.; Tsao, L.C.; Lee, C.W.; Cheng, M.Y.; Chang, C.; Yang, Y.J.; Fan, K.C. Flexible temperature sensor array based on a Graphite-Polydimethylsiloxane composite. Sensors 2010, 10, 3597-3610. [CrossRef] [PubMed]

16. Rogers, J.A.; Someya, T.; Huang, Y.; Sorensen, A.E.; Lian, J.; Greer, J.R.; Valdevit, L.; Carter, W.B.; Ge, Q.; Jackson, J.A.; et al. Materials and mechanics for stretchable electronics. Science 2010, 327, 1603-1607. [CrossRef] [PubMed]

17. Song, J. Mechanics of stretchable electronics. Curr. Opin. Solid State Mater. Sci. 2015, 19, 160-170. [CrossRef]

18. Hammock, M.L.; Chortos, A.; Tee, B.C.K.; Tok, J.B.H.; Bao, Z. 25th anniversary article: The evolution of electronic skin (E-Skin): A brief history, design considerations, and recent progress. Adv. Mater. 2013, 25, 5997-6038. [CrossRef] [PubMed]

19. Trung, T.Q.; Lee, N.E. Materials and devices for transparent stretchable electronics. J. Mater. Chem. C 2017, 5, 2202-2222. [CrossRef]

20. Dimitrakopoulos, C.D.; Malenfant, P.R.L. Organic thin film transistors for large area electronics. Adv. Mater. 2002, 14, 99-117. [CrossRef]

21. Zhou, Y.; Fuentes-Hernandez, C.; Shim, J.; Meyer, J.; Giordano, A.J.; Li, H.; Winget, P.; Papadopoulos, T.; Cheun, H.; Kim, J.; et al. A universal method to produce low-work function electrodes for organic electronics. Science 2012, 336, 327-332. [CrossRef] [PubMed]

22. Liao, C.; Zhang, M.; Yao, M.Y.; Hua, T.; Li, L.; Yan, F. Flexible organic electronics in biology: Materials and devices. Adv. Mater. 2015, 27, 7493-7527. [CrossRef] [PubMed]

23. Harrison, M.R.; Vincent, J.H.; Steen, H.A.H. Lead-free reflow soldering for electronics assembly. Solder. Surf. Mt. Technol. 2001, 13, 21-38. [CrossRef]

24. Zhou, J.; Sun, Y.; Xue, F. Properties of low melting point Sn-Zn-Bi solders. J. Alloys Compd. 2005, 397, $260-264$. [CrossRef]

25. Mir, I.; Kumar, D. Recent advances in isotropic conductive adhesives for electronics packaging applications. Int. J. Adhes. Adhes. 2008, 28, 362-371. [CrossRef]

26. Li, Y.; Wong, C.P. Recent advances of conductive adhesives as a lead-free alternative in electronic packaging: Materials, processing, reliability and applications. Mater. Sci. Eng. R 2006, 51, 1-35. [CrossRef]

27. Okamoto, M.; Kurotobi, M.; Takeoka, S.; Sugano, J.; Iwase, E.; Iwata, H.; Fujie, T. Sandwich fixation of electronic elements using free-standing elastomeric nanosheets for low-temperature device processes. J. Mater. Chem. C 2017, 5, 1321-1327. [CrossRef]

28. Mitsui, R.; Takahashi, S.; Nakajima, S.I.; Nomura, K.I.; Ushijima, H. Film-type connection system toward flexible electronics. Jpn. J. Appl. Phys. 2014, 53, 05HB04. [CrossRef]

(C) 2019 by the authors. Licensee MDPI, Basel, Switzerland. This article is an open access article distributed under the terms and conditions of the Creative Commons Attribution (CC BY) license (http://creativecommons.org/licenses/by/4.0/). 